\title{
Transient Environmental Dependency Syndrome due to Phendimetrazine Tartrate
}

\author{
Michael Hoffmann \\ Department of Neurology, University of South Florida, Tampa, Fla., USA
}

Dear Sir,

A 23-year-old healthy college student was found in a stranger's home which to the consternation of the owner she was inexplicably cleaning and tidying. She was witnessed to be making up the beds in the house, picked up cigarette butts, cleaning and wiping the furniture for about $1 \mathrm{~h}$. The owner called the local sheriff department who in turn contacted the woman's mother as the patient was able to recall her telephone number correctly. She had been jogging on a suburban trail that winds through both developed property and preserve. Her 3-4 weekly routine of jogging on that trail was no different that morning other than she had skipped breakfast. She had also been taking phendimetrazine tartrate [1] for 5 months and more recently for 2 months had added ephedrine in her quest for rapid weight reduction. The reason was a 30-pound weight gain 9 months earlier after her wedding. By that evening she appeared normal to her parents and husband, apart from agitation and hyperactivity. However, she had retrograde amnesia (approximately $8 \mathrm{~h}$ ) for the entire event since the commencement of her jogging as she could recall the exact site where she had parked her car at the trail.

\section{Examination}

She was assessed neurologically 4 days postevent. Her medical history was unremarkable with no head injury, seizure disorder or family history thereof and she was not on any other medication, was without deleterious habits or substance abuse. Her neurological examination was normal, the Mini Mental State Score was 30/30 and the abbreviated Carroll Depression Scale normal. Cognitive assessment was notable for agitation, a tendency to skip from one subject to another rapidly without completing her sentences described by her mother and dyssomnia by history. Her speech was fluent with normal comprehension, Serial 7's intact but slow, memory for 5 words at 5 min 4/5 and Luria's motor sequence test impaired. Word list generation with $\mathrm{S}$ was suboptimal with only 8 words generated in 1 min. Visuospatial function for 3-dimensional copying was impaired characterized by a perseverative tendency, copying 12 cubes instead of one. Neuroradiology by magnetic resonance imaging (T2, FLAIR, DWI, cervical and intracranial magnetic resonance angiography) was normal. Routine blood biochemistry, thyroid function tests and electroencephalog- raphy were normal. She discontinued the medication abruptly of her own accord and in a review 2 weeks later was back to her normal state as confirmed by her parents and husband. She remained without further incident or psychiatric sequelae at 6 and 12 months' follow-up.

\section{Discussion}

The differential of the clinical event includes a nonconvulsive complex partial seizure state, dissociative states such as psychogenic amnesia, psychogenic fugue, depersonalization disorder, transient global amnesia, poriomania or psychosis not otherwise specified [2]. This differential list was discounted because no new identity was reported, and she was able to recall personal information during the event (her telephone number). Seizure precipitation is a known side effect of amphetamine and derivatives and clinical resolution ensued with discontinuation of the medication.

Clinically she presents with a transient state that may be appropriately interpreted as loss of autonomy from the environment, the environmental dependency syndrome (EDS) [3]. The subsequent documentation

\section{KARGER}

Fax +4161306 1234 E-Mail karger@karger.ch www.karger.com
(C) 2007 S. Karger AG, Basel 0014-3022/07/0581-0049\$23.50/0

Accessible online at: www.karger.com/ene
Michael Hoffmann

Department of Neurology, MDC 55

University of South Florida, 12901 Bruce B. Down's Blvd

Tampa, FL 33612 (USA)

Tel. +1 813974 2794, Fax +1 813974 3160,E-Mail mhoffmann4@mac.com 
of agitation, frontal network disturbance, attention deficit hyperactivity disorder and possible seizure state is all consistent with the side effects reported for amphetamine-like substances including phendimetrazine. In the context of no previous seizure history or risk factors thereof, normal multimodality MR imaging and electroencephalography, the cause and effect relationship is bolstered. The normal electroencephalogram does not exclude a transient complex partial seizure state especially one that is not due to a structural lesion. The diagnosis of EDS as a manifestation of the transient complex seizure state is suggested because of the absence of other characteristics of a fugue-like state, and no previous clinical or current electri- cal evidence of seizure. The EDS, first described by Lhermitte et al. [4], was eloquently demonstrated by them outside the usual clinical and hospital environment as a loss of personal autonomy in patients that had frontal lobe lesions of various kinds. This is the more complex form of loss of environmental autonomy than the better known imitation behavior and utilization behavior also described by them in a two-part series. In the spectrum of manifestations that include imitation and utilization behavior, it is a dramatic and excessive dependency on environmental cues. In the described patient it was transient and this is the first such case on review of the available English medical literature.

\section{References}

1 Physician's Desk Reference. Amarin Pharmaceuticals. Montvale, Thomson Press, 2004, p 565.

2 Cummings JL, Mega MS: Dissociative states, multiple personality and hysteria; in Cummings JL, Mega MS (eds): Neuropsychiatry and Behavioral Neuroscience. Oxford, Oxford University Press, 2003, pp 333-343.

3 Lhermitte F: Human autonomy and the frontal lobes. II. Patient behavior in complex and social situations. The 'environmental dependency syndrome'. Ann Neurol 1986;19:335343

4 Lhermitte F, Pillon B, Serdaru M: Human autonomy and the frontal lobes. I. Imitation and utilization behavior: a neuropsychological study of 75 patients. Ann Neurol 1986;19: 326-334. 